\title{
ДУАЛЬНИЙ СПОСТЕРІГАЧ ЯК КОМПЕНСАТОР НЕКОНТРОЛЬОВАНИХ ЗБУРЕНЬ
}

\begin{abstract}
Анотація: Робота присвячена використанню дуального спостерігача в адаптивних системах автоматичного керування. Описується новий принцип побудови систем, здатний значно підвищити якість їх роботи. Наводяться результати експериментальних досліджень перехідних процесів у системах керування з дуальним спостерігачем.

Ключові слова: система керування, інваріантність, спостерігач стану, нулі, полюси, компенсуючий вплив, неконтрольована завада.
\end{abstract}

\section{Вступ}

Однією із задач системи автоматичного керування $е$ визначення та реалізація такого керуючого впливу на об'єкт керування, щоб його керована величина змінювалася відповідно заданої цілі керування із заданою точністю незалежно від дії зовнішнього збурення. Задача компенсації зовнішніх збурень, які можуть спостерігатися, вирішуеться на основі другого методу інваріантності за рахунок включення в систему керування каналу компенсації такого збурення, і тому вважається тривіальною. Методи теорії інваріантності набувають особливе значення, коли зовнішні збурення та інші перешкоди, які визивають непередбачену зміну параметрів системи керування , $е$ неконтрольованими. Відомо $[1,2]$ що застосування коректуючого ланцюга в другому каналі передачі задавальної величини з передаточною функцією аналогічною заданої системі керування можна значно зменшити вплив збурення на керовану величину. У роботах $[3,4,5]$ було запропоновано один із можливих методів реалізації поставленої задачі на основі застосування дуального спостерігаючого пристрою (дуального спостерігача ДС). за допомогою якого керована змінна стану об'екта керування змінюеться за рахунок компенсую чого керуючого впливу, який визначаеться на основі фрункціонального зв'язку різниці вимірюваних значень керованої величини та сигналу на виході дуального спостерігача.

\section{Постановка задачі}

Класичний спостерігаючий пристрій СП [2] застосовуеться для оцінки змінних стану об'єкта керування за рахунок включення компенсуючи зв'язків (матриці L), які впливають на змінні стану моделі, адекватної передаточної функції об'єкту, таким чином, щоб налаштувати ці змінні стану з умови незміщених оцінок, тобто $\hat{x}_{i}(t)=x_{i}(t)$. Цей метод доцільно використовувати тільки при невідомих початкових умовах, тобто при невизначених значеннях $x_{i}(0)$, або змінних стану, що не спостерігаються. Якщо на об'єкт керування буде діяти зовнішне збурення, то змінні стану не відновлюються (рис. 1).

(c) C.В. Шпіт, I.М. Кучер, А.В. Мойсеєнко, А.В. Какотко, 2012 


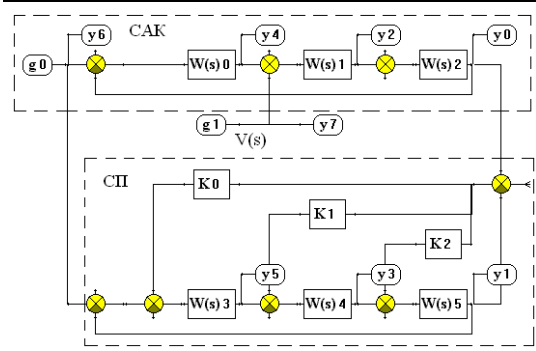

a) структурна схема

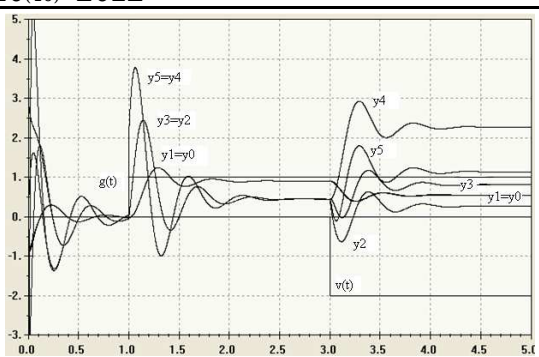

б) перехідні процеси

Рис. 1 - Спостерігач стану

Якщо змінити напрямок включення компенсуючи зв'язків [3] (рис. 2), тобто впливати на змінні стану об'єкта керування $x_{i}(t)$, то вони будуть налаштовуватися на змінні стану спостерігаючого пристрою, координати об'єкта будуть наближатися до координат СП Тому що такий СП вирішуе зворотню задачу, то будемо називати його дуальним спостерігаючим пристроєм (дуальним спостерігачем ДС).

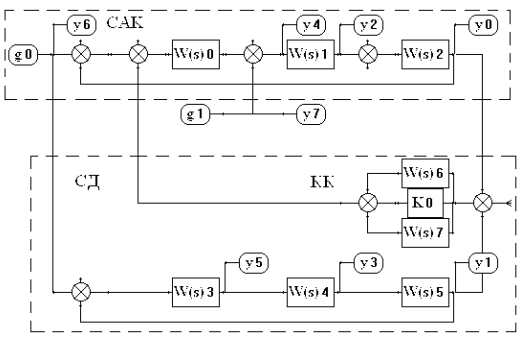

a) структурна схема

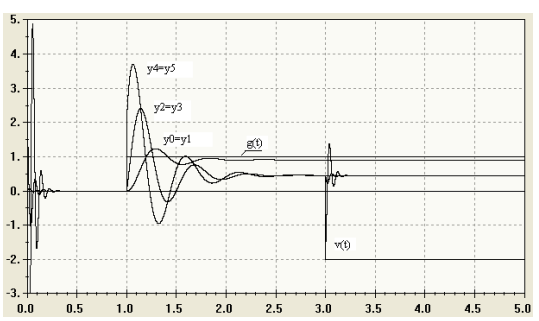

б) перехідні процеси

Рис. 2 - Система керування з ДС

Але необхідно визначити, що у більшості випадків не представляється можливість безпосередне (різичні обмеження, тощо) впливати на всі змінні стану об'єкта керування. В цьому разі якщо $y(t) \neq y_{m}(t)$, то ДС включається в керуючу підсистему, яка виробляе додатковий керуючий вплив $\Delta u(t)$, за допомогою якого керована величина наближається до заданої незалежно від наслідків. які вивели їі із стану рівноваги, тобто одночасно може вирішуватися і задача стійкості (рис. 2б).

Розглянемо основний принцип побудови систем з еталоном спостерігачем на прикладі одномірної системи керування (рис. 3).

Керована величина при $V(s)=0$ визначається як

$$
\begin{gathered}
y_{0}(s)=W_{1}(s) W_{0}(s) g(s)-W_{1}(s) W_{0}(s) y_{0}(s)+ \\
+W_{1}(s) W_{0}(s) W_{L}(s) y_{M}(s)-W_{1}(s) W_{0}(s) W_{L}(s) y_{0}(s) .
\end{gathered}
$$

З урахуванням $y_{M}(s)=W_{M}(s) g(s)$ з рівняння (1) отримуемо 


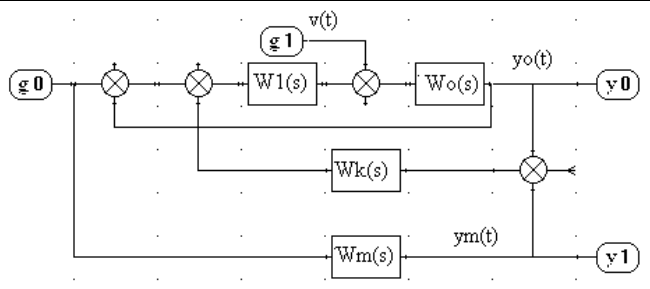

Рис. 3 - Одномірна система із еталоном-спостерігачем

$$
\left[1+W_{1}(s) W_{0}(s)\left(1+W_{L}(s)\right)\right] y_{0}(s)=W_{1}(s) W_{0}(s)\left[1+W_{L}(s) W_{M}(s)\right] g(s) .
$$

Тоді

$$
y_{0}(s)=\frac{W_{1}(s) W_{0}(s)+W_{L}(s) W_{M}(s) W_{1}(s) W_{0}(s)}{1+W_{1}(s) W_{0}(s)+W_{L}(s) W_{1}(s) W_{0}(s)} g(s) .
$$

Якщо вибрати $W_{L}(s) \gg 1$, то

$$
y(s) \approx W_{M}(s) g(s) .
$$

Таким чином, якщо забезпечити умови стійкості та надати контуру автопідстроювання $W_{L}(s)$ астатичні властивості, тобто обрати у вигляді ПІД структури, то вихід об'екта керування буде залежним тільки від передаточної функції спостерігача $W_{L}(s)$. При цьому значно спрощуеться задача синтезу системи керування із заданими показниками якості за рахунок вибору спостерігача з передаточною функцією зниженого порядку.

Розглянута структура забезпечуе виконання умов інваріантності систем керування до дії неконтрольованих збуджень. Якщо збурення прикладаються до об’екта керування, то відповідно рис. 1 будемо мати:

$$
\begin{gathered}
y_{0}(s)=\frac{W_{1}(s) W_{0}(s)\left[1+W_{L}(s) W_{M}(s)\right]}{1+W_{1}(s) W_{0}(s)\left[1+W_{L}(s)\right]} g(s)- \\
-\frac{W_{0}(s)}{1+W_{1}(s) W_{0}(s)\left[1+W_{L}(s)\right]} V(s)=y_{g}(s)-y_{V}(s) .
\end{gathered}
$$

Тоді з урахуванням $W_{L}(s) \rightarrow \infty$ буде виконуватися умова

$$
y_{V}(s)=-\frac{W_{0}(s)}{1+W_{1}(s) W_{0}(s)\left[1+W_{L}(s)\right]} V(s) \rightarrow 0 .
$$

Якщо $W_{L}(s)=\frac{K_{L}}{s}$, то

$$
\begin{gathered}
y_{V}(s)=-\frac{W_{0}(s)}{1+W_{1}(s) W_{0}(s)\left[1+\frac{K_{L}}{s}\right]} V(s)=-\frac{s W_{0}(s)}{s+W_{1}(s) W_{0}(s)\left[s+K_{L}\right]} V(s) \\
\lim _{t \rightarrow \infty} y_{V}(t)=\lim _{s \rightarrow 0} s y_{V}(s)=\lim _{s \rightarrow 0} s \frac{s W_{0}(s)}{s+W_{1}(s) W_{0}(s)\left[s+K_{L}\right]} \frac{V_{0}}{s} \rightarrow 0 .
\end{gathered}
$$


Отже, теоретичні та експериментальні дослідження співпадають (див. рис. 2б).

На основі наведених висновків можна стверджувати, що динамічні властивості системи керування можна змінювати за допомогою ДС. При цьому бажані властивості визначаються структурою та параметрами $W_{M}(s)$. Будемо називати полюси передаточної функції $W_{M}(s)$ домінуючими полюсами.

\section{Лемма 1.}

Якщо загальна передаточна функція (3) системи керування $W(s)=$ $\frac{W_{1}(s) W_{0}(s)+W_{L}(s) W_{M}(s) W_{1}(s) W_{0}(s)}{1+W_{1}(s) W_{0}(s)+W_{L}(s) W_{1}(s) W_{0}(s)}$ із ДС буде утримувати нулі, які будуть компенсувати не домінуючи полюси, то вихідний сигнал $y_{0}(t)$ об'єкта керування в процесі самонастроювання буде наближатися до $y_{m}(t)$. Дійсно, якщо задана система визначається передаточною функцією $W_{z 0}(s)$ замкнутої системи.

$$
W_{P}(s)=\frac{0.22(2 s+1)}{s(0.228 s+1)(0.686 s+1)} W_{Z}(s)=\frac{W_{P}(s)}{1+W_{P}(s)}
$$

А бажаний рух задається передаточною функцією СД $W_{M}(s)$, яка задає домінуючі полюси

$$
W_{M}(s)=\frac{1.25}{0.25 s^{2}+s+1.25}
$$

(відповідні перехідні процеси для даного випадку представленні на Рис. 4), то при включенні каналу компенсації $W_{k}(s)$ у вигляді ПІД-Р

$$
W_{K}(s)=100+\frac{25 s}{0.01 s+1}+\frac{10}{s}
$$

в системі керування з включеному СД перехідний процес $y_{0}(t)$ збігаеться із бажаним $y_{m}(t)$, тобто передаточна функція

$$
W(s)=\frac{W_{P}(s)+W_{P}(s) W_{K}(s) W_{M}(s)}{1+W_{P}(s)+W_{P}(s) W_{K}(s)}
$$

утримуе домінуючі нулі та полюси

$$
\begin{aligned}
& W(s) \begin{array}{l}
\text { simplify } \\
\text { float }, 4
\end{array} \rightarrow .2750 e 5(2 s+1) . \\
& \cdot \frac{s^{4}+104 s^{3}+.1341 e 5 s^{2}+.5055 e 5 s+5000}{\left(.1955 e 5 s^{5}+.2069 e 7 s^{4}+.1546 e 9 s^{3}+.6401 e 9 s^{2}+.3330 e 9 s+.2750 e 8\right)\left(s^{2}+4 s+5\right)}
\end{aligned}
$$

Домінуючі полюси $W_{M}(s)$

$$
0.25 s^{2}+s+1.25 \mid \begin{aligned}
& \text { solve, } s \\
& \text { float }, 4
\end{aligned} \rightarrow\left[\begin{array}{l}
(-2)-1 i \\
(-2)+1 i
\end{array}\right] .
$$

Нулі та полюси, які з'являються в САК в результаті дії СД: 


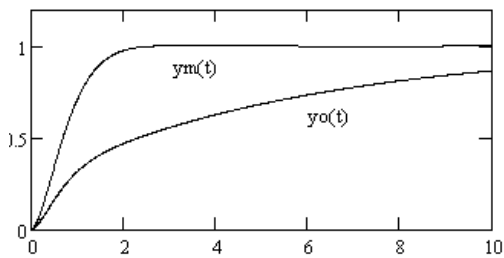

a) вимкнутий СД

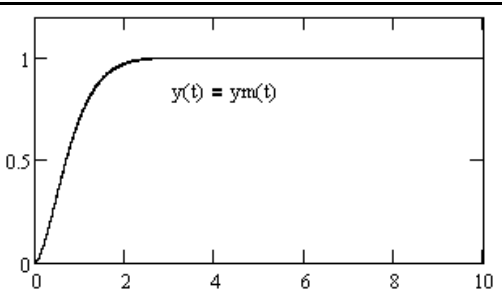

б) включений СД

Рис. 4 - Перехідні процеси

нулі $W(s)$

$$
\begin{aligned}
& 27500(2 s+1)\left(s^{4}+104 s^{3}+13405 s^{2}+50550 s+5000\right) \\
& \mid \begin{array}{l}
\text { solve, } s \\
\text { float, } 4
\end{array} \rightarrow\left[\begin{array}{l}
-5000 \\
(-50.06)-102.5 i \\
(-50.06)+102.5 i \\
-3.779 \\
-.1016
\end{array}\right]
\end{aligned}
$$

полюси $W(s)$

$$
\begin{aligned}
& \left(19551 s^{5}+2069350 s^{4}+154605000 s^{3}+640077500 s^{2}+\right. \\
& +333025000 s+27500000)\left(s^{2}+4 s+5\right) \mid \begin{array}{l}
\text { solve, } s \\
\text { float }, 4
\end{array} \rightarrow\left[\begin{array}{l}
(-50.74)-69.92 i \\
(-50.74)+69.92 i \\
-3.763 \\
-.4904 \\
-.1021 \\
(-2)-1 i \\
(-2)+1 i
\end{array}\right]
\end{aligned}
$$

Домінуючі полюси $-2 \pm 0.1 i$ зберігаються.

Нуль з малою дійсною частиною -0.1021 компенсуе відповідний полюс -0.1016 . Полюси передаточної функції САК $W(s)$ добре компенсуються відповідними нулями. Перехідний процес $y(t)$ співпадае із заданим рухом $y_{m}(t)$.

Аналіз дії збуджуючих впливів (неконтрольованих) виконувався на моделюючому комплексі "SHS-TAK", який було розроблено на кафедрі Технічної кібернетики Національного технічного університету України "КПІ" під керівництвом доцента Шпіт С.В. Дослідження виконувалися при дії детермінованих та випадкових неконтрольованих впливах, які прикладалися до різних точок системи керування. Для контролю результатів роботи дуального спостерігача застосовувалась також контрольна система керування, на яку діяли ті ж самі збудження. На рис. 5 представлено структурну схему САК з дуальним спостерігачем ДС. Для порівняння дії неконтрольованих впливів неконтрольовані впливи подаються також на контрольну САК.

Результати експериментів приведені на рис. 6 а-г. На рис. 6а приведені експериментальні перехідні процеси в системі із ДС та контрольної 


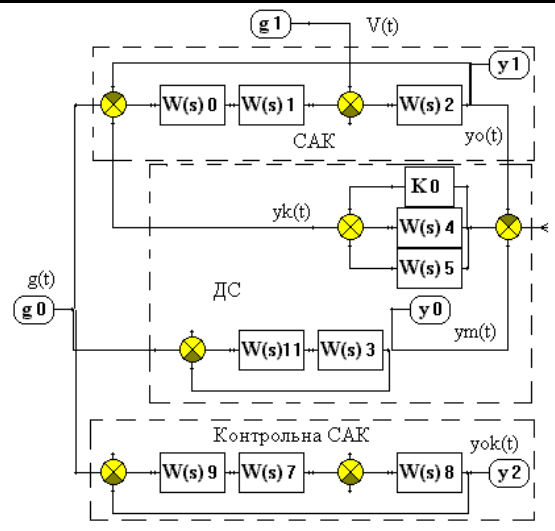

Рис. 5 - Експериментальна схема САК з ДС

САК при дії завади на об'ект керування. В результаті дії ДС керована величина $y_{0}(t)$ змінюеться за законом $y_{m}(t)$, тобто $y_{0}(t)=y_{m}(t)$, що відповідає умовам (4). Дія збуджуючого впливу $V(t)$ практично компенсуеться без похибки, виконуеться умова (7). Результати дії $V(t)$ в режимі переключення приведені на рис. 6 б. Найважчий для системи режим компенсації неконтрольованої завади виникає у при дії завади безпосередньо на виході об’екта керування (рис. 6 в, г). В цьому разі виникають незначні динамічні похибки значно менше ніж у контрольної системі $y_{o k}(t)$. Дія випадкового впливу (рис. 7) компенсуеться з величиною відхилення $1 \%$ (рис. 7 б)

\section{Висновки}

Теоретичні та експериментальні дослідження побудови автоматичних систем керування з дуальним спостерігачем показали високу ефективність запропонованих методів при значному спрощенні їх фрізичної реалізації. При цьому знімається проблема корекції параметрів як об'єкта керування так і регулятора, а сама система керування набуває властивостей інваріантності до впливу неконтрольованих завад у широкому діапазоні.

\section{Література}

1. Петров Б.Н. Принцип инвариантности и условия его применения при расчете линейных и нелинейных сисмем, Труды I Конгресса ИФАК, т. 1, 1960.

2. Тютюнник А.Г. Оптимальні і адаптивні системи автоматичного керування: Навчальний посібник. Житомир: ЖІТІ, 1998. - 512 с.

3. Шпіт С.В., Янцеловський С.Г., Ткаченко О.І. Системи автоматичного керування з еталоном - спостерігачем // Адаптивнісистеми автоматичного управління. -2008-№12(32).- с. 145 - 151. 

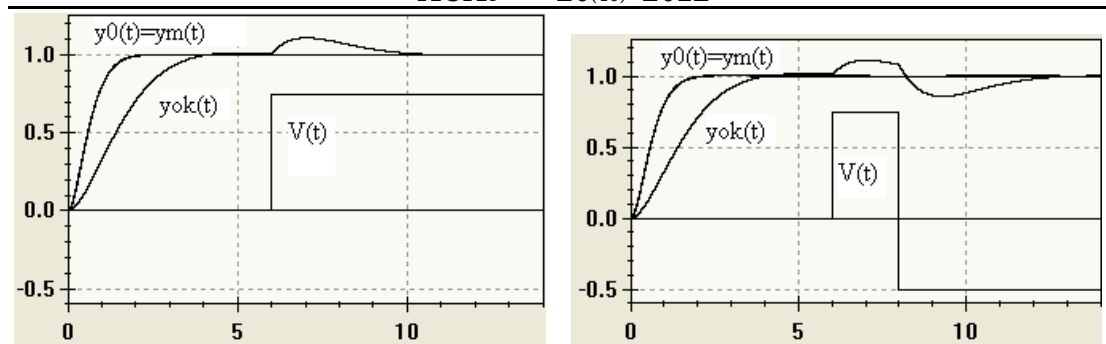

a)

б)
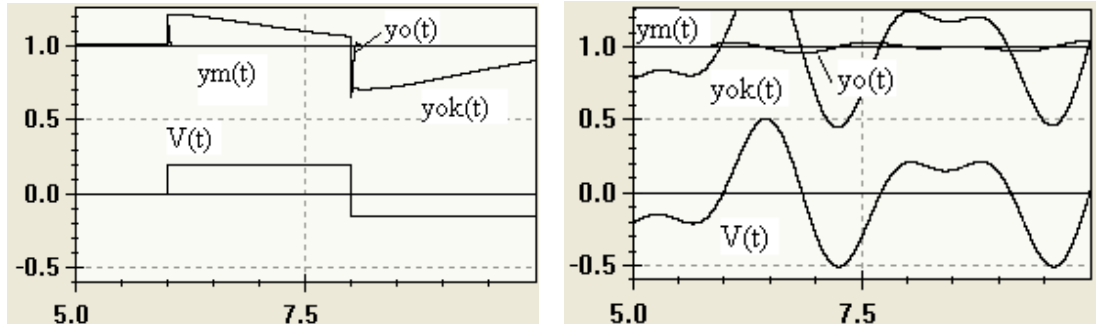

B)

г)

Рис. 6 - Дія нерегулярної завади на виході САК

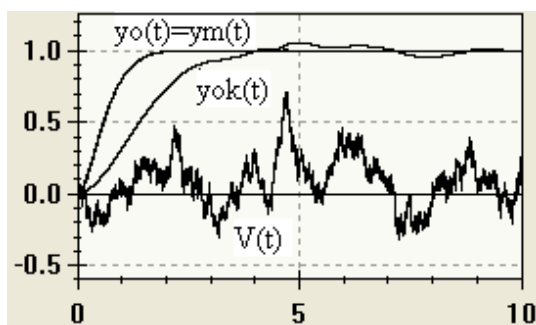

a)

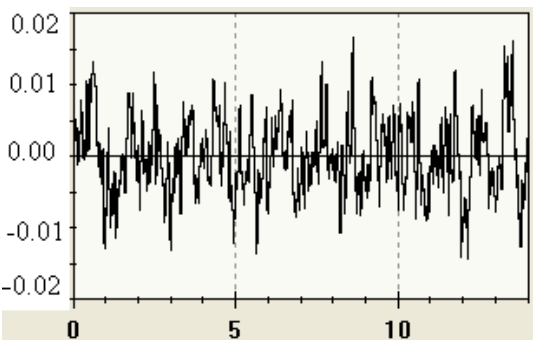

б)

Рис. 7 - Результат дії випадкової завади

4. Шпіт С.В., Семчишин А.В. Автономна багатомірна система керування з еталонами - спостерігачами // Адаптивнісистеми автоматичного управління. -2009 - №13(33).- с. .

5. Шпіт С.В. Дуальнийспостерігач в системах автоматичного керування // Адаптивні системи автоматичного управління. -2009 №14(34).- c. .

Отримано 17.02.2012 p. 